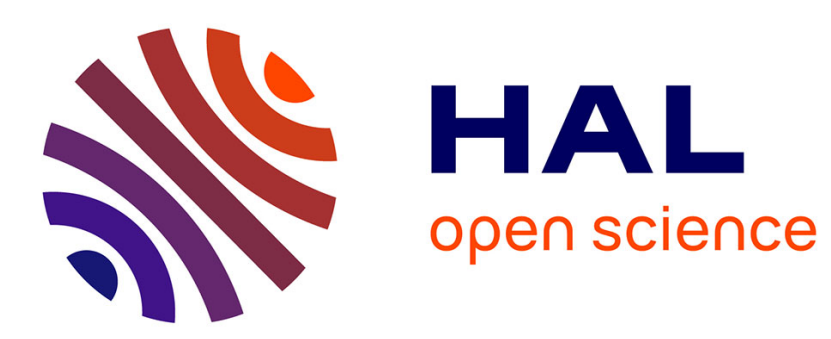

\title{
Improvement of product design process by knowledge value analysis
}

Yang Xu, Alain Bernard, Nicolas Perry, Florent Laroche

\section{To cite this version:}

Yang Xu, Alain Bernard, Nicolas Perry, Florent Laroche. Improvement of product design process by knowledge value analysis. CIRP Design 2012 - Sustainable Product Development, Springer, pp.2072016, 2013, 10.1007/978-1-4471-4507-3_20 . hal-00941059

\section{HAL Id: hal-00941059 \\ https://hal.science/hal-00941059}

Submitted on 4 Feb 2014

HAL is a multi-disciplinary open access archive for the deposit and dissemination of scientific research documents, whether they are published or not. The documents may come from teaching and research institutions in France or abroad, or from public or private research centers.
L'archive ouverte pluridisciplinaire $\mathbf{H A L}$, est destinée au dépôt et à la diffusion de documents scientifiques de niveau recherche, publiés ou non, émanant des établissements d'enseignement et de recherche français ou étrangers, des laboratoires publics ou privés. 


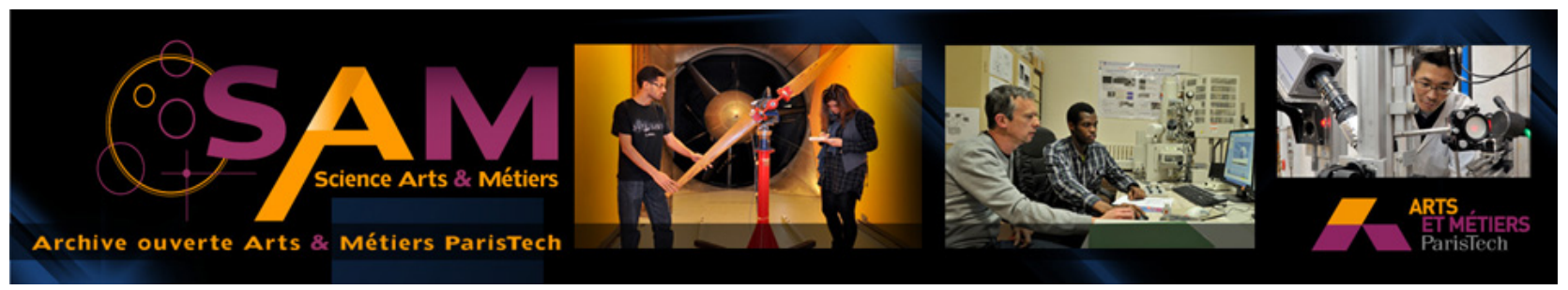

Science Arts \& Métiers (SAM)

is an open access repository that collects the work of Arts et Métiers ParisTech researchers and makes it freely available over the web where possible.

This is an author-deposited version published in: http://sam.ensam.eu Handle ID: .http://hdl.handle.net/10985/7738

\section{To cite this version :}

Yang XU, Alain BERNARD, Nicolas PERRY, Florent LAROCHE - Improvement of product design process by knowledge value analysis - 2013 


\title{
Improvement of product design process by knowledge value analysis
}

\author{
Yang XU ${ }^{\mathrm{a}}$, Alain BERNARD ${ }^{\mathrm{b}}$, Nicolas PERRY ${ }^{\mathrm{c}}$, Florent LAROCHE \\ CIRP Design 2012 - Sustainable Product Development - 2013, pp 207-216 \\ a Peking University - Department of Information Management, Ch100871 Beijing \\ yang.xu@pku.edu.cn \\ b IRCCyN UMR CNRS 6597 - Ecole Centrale de Nantes, F4400 Nantes \\ alain.bernard@irccyn.ec-nantes.fr \\ c Arts et Métiers ParisTech - I2M UMR 5295, F33400 Talence \\ n.perry@i2m.u-bordeaux1.fr
}

\begin{abstract}
Nowadays, design activities remain the core issue for global product development. As knowledge is more and more integrated, effective analysis of knowledge value becomes very useful for the improvement of product design processes. This paper aims at proposing a framework of knowledge value analysis in the context of product design process. By theoretical analysis and case study, the paper illustrates how knowledge value can be calculated and how the results can help the improvement of product design process, such as deciding which knowledge to choose and what to do next.
\end{abstract}

\subsection{Introduction}

In this world of globalization, more and more enterprises consider knowledge management (KM) process as an important part, if not the only part, of their production activities (Nonaka and Takeuchi, 1995; Bernard and Tichkiewitch, 2008). Meanwhile, how to pay deeper attention to the crucial competence "knowledge" is becoming a strategic approach in production management, and product design process is linked more and more tightly with knowledge (Perry et al., 2011).

When considering knowledge management in product design activities, how to evaluate knowledge has always been a challenging problem. Which knowledge is more "useful" and thus can add more value to the product? What knowledge to be acquired in the next step of design? The answers of such questions may greatly improve design activities, so the following sections will focuses on this related issue: how to calculate and analyze knowledge value in product design processes and help them improve. 


\subsection{How to evaluate knowledge value}

\subsubsection{Product development process}

We may describe the product development process as the following procedure: a product starts from its initial state and arrive to a required state (final state), and a task $T$ is supposed to be accomplished to realize this product evolution from that initial state $P_{0}$ to the final state $P_{n}$. The product development process can be described by a series of state changes. Given an initial state $P_{0}$, the product development process can be characterized by a sequence of product states « $P_{0} \rightarrow P_{1} \rightarrow P_{2} \rightarrow \cdots \rightarrow P_{n}$ ", where $P_{1}$ is the product state when $t_{1}$ is accomplished, $P_{2}$ is the product state when $t_{2}$ is accomplished, etc., and when task $T$ is accomplished, the product comes to its final state $P_{n}$.

Task $T$ can be defined as follow.

Definition 1. Task $T$ is represented by a weighted directed graph $G(T)=(H, A, \Omega)$, where:

- $\quad H$ is a set of tasks, whose elements are the task $T$, the non-atom tasks $t_{m}$ and the atom-tasks $a t_{n}$, i.e., $H=\left\{h_{i}\right\}=\left\{T, t_{1}, t_{2}, \ldots, t_{m}, a t_{1}, a t_{2}, \ldots, a t_{n}\right\}$;

- $\quad A$ is a set of directed arcs $\alpha_{p q}$, i.e. $h_{p}$ and $h_{q}$ are linked by $\alpha_{p q}$, from $h_{p}$ to $h_{q}$;

- $\Omega$ is a set of weights $\omega_{p q}$ which are assigned to each $\operatorname{arc} \alpha_{p q}$.

Particularly, the sub-tasks which do not have successors are named atom-tasks, noted as $a t_{i}$.

The reason that $T$ is characterized by a graph, not a tree, is that there may be several sub-tasks which are not independent and they may have one or several sub-tasks in common. 


\subsubsection{Knowledge value}

Supposing that knowledge $K$ is necessary to accomplish the task $T$ and knowledge fragment $k_{i}$ is needed to accomplish sub-task $t_{i}$, thus, $k_{i}$ is the solution for the sub-task $t_{i}$, and knowledge $K$ can be considered as a set of solutions which together can accomplish the task $T$. Obviously, a knowledge fragment $k_{i}$ can be a person, a book, a plan or any type of solutions provided, and knowledge characterization in detail can be referred from the works of $\mathrm{Xu}$ and Bernard (2010a).

Based on this proposal, some questions may be raised. Is knowledge $K$ can accomplish the task $T$ completely? If knowledge $K$ can only solve a part of the task $T$, which part is solved? What knowledge fragments $k_{i}$ have to be added in order to solve the remaining parts? How to choose the knowledge fragments $k_{i}$ to accomplish the unsolved sub-tasks?

In order to answer these questions, some hypotheses are firstly presented:

Hypothesis 1. The atom-tasks are noted as $a t_{i}$, and all atom-tasks correspond to an explicit answer "yes" or "no" which shows whether it can be solved or not. In other words, the atom-tasks cannot be solved partially.

Hypothesis 2. The principles of task decomposition are as follows.

If the task $T$ is decomposed into $T_{1}, T_{2}, \ldots, T_{n}$, we have:

a. $\quad T \subset\left(T_{1} \cup T_{2} \cup \ldots \cup T_{n}\right)$

(The combination of the sub-tasks should cover the original task $T$ )

b. $T \not \subset T_{i}$

(Any sub-task $T_{i}$ cannot cover the original task $T$ )

c. The task $T$ is decomposed with weights, noted as:

$$
T: \omega_{1} T_{1}+\omega_{2} T_{2}+\ldots+\omega_{n} T_{n} \text {, and } \sum_{i=1}^{n} \omega_{i}=1
$$

(The weights indicate the importance of the sub-tasks to the original task, for example, if the design of a car focuses more on speed improvement, then the sub-task of speed improvement will have a higher weight than the sub-task of cost diminution) 
The value of knowledge $K_{i}$ to the task $T_{i}$ is noted as $V\left(T_{i}, K_{i}\right)$. This notation indicates that knowledge is always in context, in other words, knowledge evaluation is linked with specific tasks. Knowledge value thus varies according to different tasks. For example, given a same knowledge fragment "to adjust the height of a chair", it could have a high value to the task "to consider the ergonomics" and have a low value to the task "to control the cost". The value of knowledge $K$ to the atom-task $a t_{i}$ is defined as follows.

Definition 2. $V\left(a t_{i}, K\right)= \begin{cases}1, & a t_{i} \text { can be solved by } K \\ 0, & a t_{i} \text { can not be solved by } K\end{cases}$

Based on the two hypotheses and Definition 2, knowledge value can be measured by the procedure as follow.

Procedure for knowledge value measurement:

Step 1: All the value of knowledge $K$ to the atom-tasks is obtained according to Definition 2.

Step 2: For any $h_{i} \in H$, find all the $\left(h_{i}, h_{j}\right)$ and their associate $\omega_{i j}$, then:

$$
V\left(h_{i}, K\right)=\sum_{j} \omega_{i j} \cdot V\left(h_{j}, K\right)
$$

The procedure shows that from Step 1 we can obtain all the $V\left(a t_{i}, K\right)$ and from Step 2 we can obtain $V(T, K)$. When $V(T, K) \neq 1$, it means there are one or several sub-tasks which are not accomplished, so additional knowledge is necessary to make $V(T, K)=1$. During this process of knowledge addition, both explicit knowledge and tacit knowledge might be needed. Usually, explicit knowledge comes from databases, publications, rules, etc. and tacit knowledge comes from experience, expertise, wisdom, judgment, etc.

If $K_{i}$ can solve $a t_{i}$ and $a t_{i}$ is linked to $T$ by a sequence of arcs with weights of $\omega_{1}, \omega_{2}, \ldots, \omega_{m}$, then

$$
V\left(T, K_{i}\right)=\prod_{u=1}^{m} \omega_{u} \cdot V\left(a t_{i}, K_{i}\right)=\omega_{a t_{i}} \cdot V\left(a t_{i}, K_{i}\right)
$$

This calculation process is realized by a calculator called CAL-KNOW, which is used in case study introduced latter.

If two knowledge fragment $K_{1}$ and $K_{2}$ are both available, $V\left(T, K_{1}\right)$ and $V\left(T, K_{2}\right)$ can be calculated and compared. Generally, knowledge that has a 
higher value is usually chosen. As collaborative networks is regarded as a critical success factor to achieve product innovation (Perry et al., 2010), it is always useful to choose the most valuable knowledge to be exchanged and shared.

\subsection{Knowledge evaluation in product design process}

During product lifecycle design, which can be defined as a sequence of tasks (Nacsa et al., 2005), both tacit and explicit knowledge may be required to accomplish the tasks $a t_{i}$, so these two kinds of knowledge can add value to the knowledge of design $K$ and thus make knowledge evolution (Bernard and $\mathrm{Xu}$, 2009; Xu and Bernard, 2010b).

Here are the main steps to take during the procedure of knowledge evaluation in supporting product design.

1. To decompose of the product development process into simpler processes, in other words, to realize the decomposition of the task $T$ into atom-tasks $a t_{i}$.

2. To evaluate the value of the existing knowledge using the evaluation model introduced in the previous section.

3. If not all the atom-tasks are solved, find out which $a t_{i}$ should be solved next.

4. To add appropriate knowledge, explicit and/or tacit, to accomplish $a t_{i}$.

5. Do Step 3 and Step 4 repeatedly until all atom-tasks are solved.

In the product design process, knowledge mat add value to products and product may also make knowledge more valuable (Xu and Bernard, 2011), and such mutual value adding process can be explicitly describe and controlled using our knowledge evaluation model.

\subsection{Case Study}

This paper has chosen a case of chair design, which is a part extracted from the product lifecycle of a chair. The concentration is implemented on the phase of design as it is a key phase where major decisions are made concerning knowledge. In this example, the task «design a chair » should be accomplished in order to make the product (chair) evolves in the development process. Figure 1(1) and Figure 1(2) illustrate how the task is decomposed. Although the decomposition is lack of completeness, for example, several tasks such as market study, packaging and 
logistics matters, particular optimization, etc., are neglected, it can serve as an adequate demonstration.

Based on the criteria obtained from experience in product design, the principle task « design a chair » is decomposed into four sub-tasks.

The weights $\omega_{i}$ are given by the experts of different roles who have different points of view in design activities. Table 1 shows the weights given to each subtask by experts of different roles. In order to determine a weight, we have taken into account the results given by a group of experts for each given role. How to improve the results of collecting and analyzing the weight values given by different people is another complicated topic, which needs further researches on statistical techniques, human behaviors, etc., and in this paper, we simply regard the weight value as is the average of the weights proposed by all the experts assigned in each group.

Table 1.1 The values of weights

\begin{tabular}{ccccc}
\hline $\begin{array}{c}\text { Experts of dif- } \\
\text { ferent roles }\end{array}$ & $\omega_{A}$ Comfort/aesthetics & $\begin{array}{c}\omega_{B} \text { Dimen- } \\
\text { sion/Mechanics }\end{array}$ & $\begin{array}{c}\omega_{C} \\
\text { Costs }\end{array}$ & $\begin{array}{c}\omega_{D} \\
\text { End of life }\end{array}$ \\
\hline Client & $50 \%$ & 10 & $30 \%$ & $10 \%$ \\
Designer & $10 \%$ & $50 \%$ & $30 \%$ & $10 \%$ \\
Manufacturer & 0 & $30 \%$ & $50 \%$ & $20 \%$ \\
Seller & $30 \%$ & $10 \%$ & $40 \%$ & $20 \%$ \\
Transporter & 0 & $60 \%$ & $30 \%$ & $10 \%$ \\
Recycler & 0 & 0 & $30 \%$ & $70 \%$ \\
\hline
\end{tabular}

Here are some illustrations about Figure 1.1:

- «Perception test » and «To consider the psychological comfort issues » can be solved by questionnaire surveys.

- «Ergonomic studies » mainly focus on examining the degree of fatigue of different parts of the body (muscle, bone, joint, etc.) of a person who sits in the chair for a period of time or by simulations.

- «Tests of the material attributes » may include the thermal conductivity (in winter, people do not like to sit in a chair with a surface of iron, because it's too cold), the sensation of the material (for example, smooth or rough, soft or hard), etc.

- «To consider the aesthetics of the chair» considers the intrinsic beauty of the chair, which depends on the cultural and social context. In other words, for a same chair, it may vary from beautiful to disgusting due to different tastes of people from different countries or groups. 


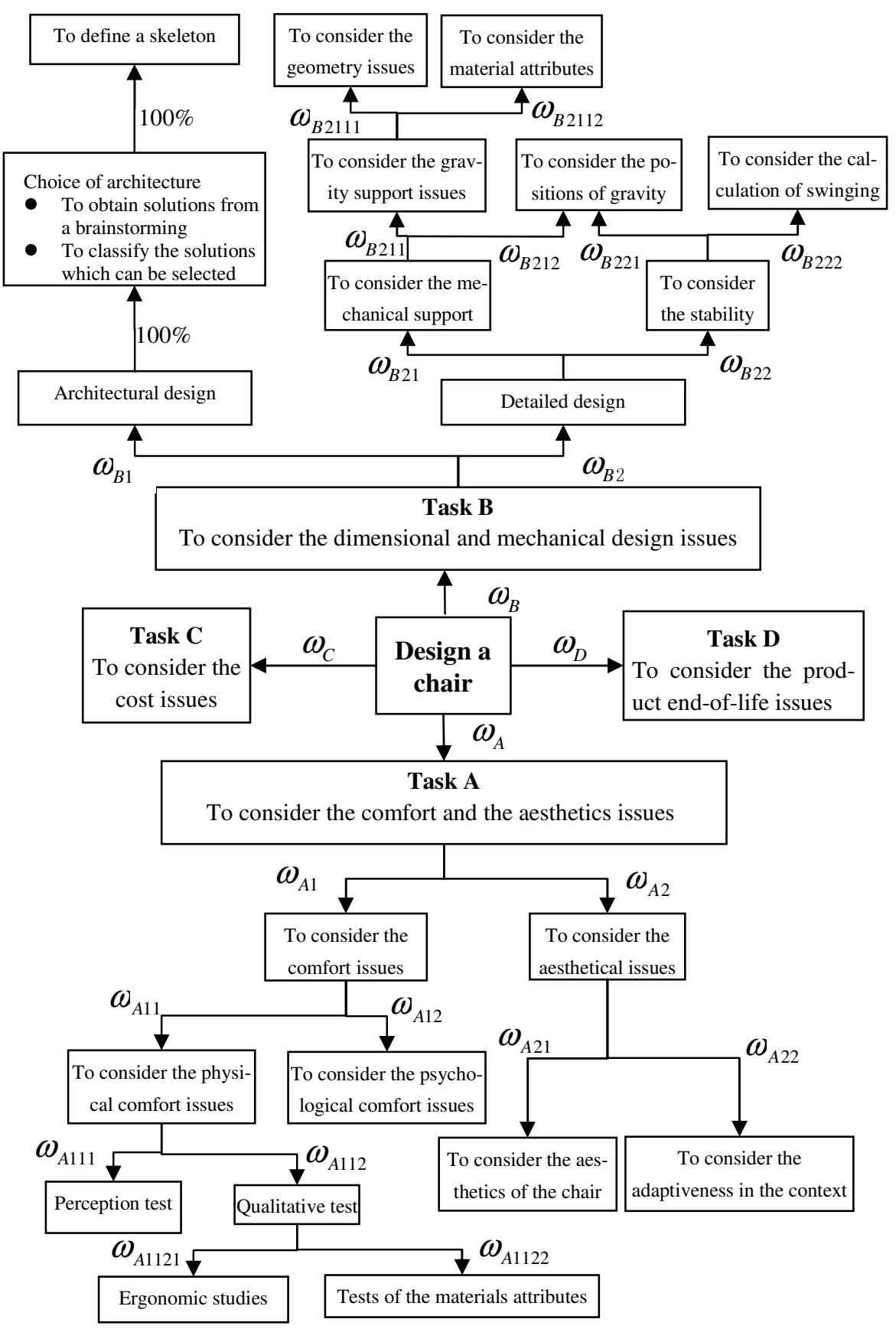

Fig. 1.1(1) The decomposition of the task « design a chair » (Part I) 


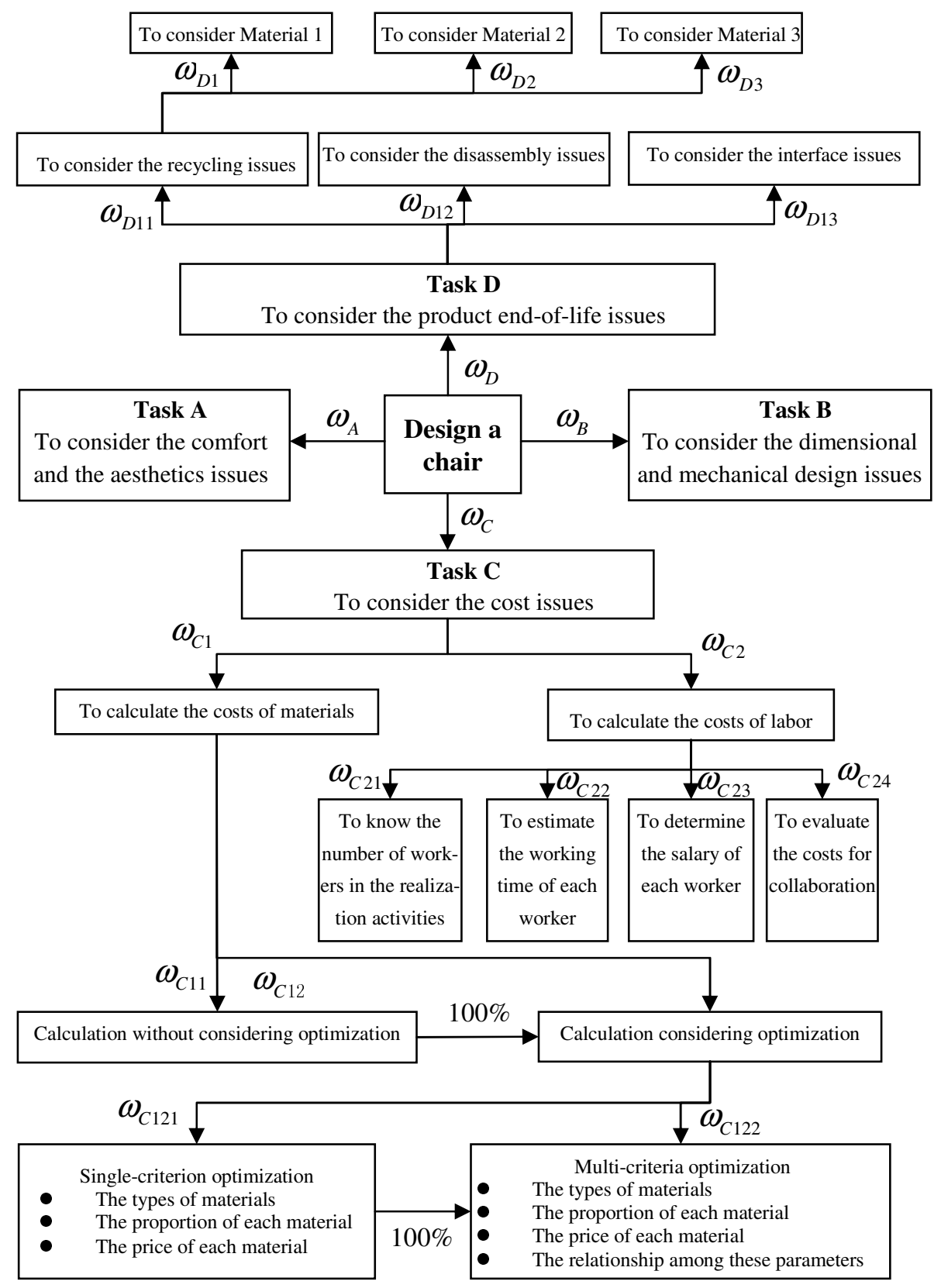

Fig. 1.1(2) The decomposition of the task « design a chair » (Part II) 
- «To consider the adaptiveness in the context of use » considers whether the chair matches the environment of use. For example, in a fast-food restaurant, sofas are not suitable to the environment although they are very beautiful.

- «Architectural design » is considered before the design in details.

- For the assignments of the values of the weights $\omega_{B 1}$ and $\omega_{B 2}$, they depend on whether the designer take optimization into account. Table 2 shows two examples in determining $\omega_{B 1}$ and $\omega_{B 2}$. In an extreme situation, when a designer assigns $\omega_{B 1}=100 \%$, it means the designer will simply look for a solution in a database of archived designs.

Table 1.2 The values of the weights $\omega_{B 1}$ and $\omega_{B 2}$

\begin{tabular}{lcc}
\hline & $\omega_{B 1}$ & $\omega_{B 2}$ \\
\hline $\begin{array}{l}\text { If the designer pay much attention in optimization issues during } \\
\text { the design process }\end{array}$ & $30 \%$ & $70 \%$ \\
$\begin{array}{l}\text { If the designer do not wish to spend too much time in searching for } \\
\text { optimization solutions for Task B }\end{array}$ & $50 \%$ & $50 \%$ \\
\hline
\end{tabular}

- The tasks «To consider the mechanical holding issues » and «To consider the stability » have a same sub-task «To consider the positions of gravity centers ». Such situation that several tasks may have a same sub-task in common is acceptable according to Definition 1 which defined the Task $T$ as a graph.

- Here are two weights which have the value «100\%». They mean that the tasks linked by an arrow of a weight of «100\%» are « equal». In this case, when people have accomplished «to define a skeleton », they have accomplished the «architectural design » at the same time.

- In order to determine the values of the weights $\omega_{C 1}$ and $\omega_{C 2}$, the context of design should be considered, in other words, they depend on the amount of production of the chairs provided by customers. Table 3 gives two examples. In the condition that the chair is designed to be produced in large quantities, the cost of materials has a weight of greater importance. When it is a case of custom design, the weight of materials is lower. The client is willing to pay the extra cost for differentiation even if the materials used are more expensive. 
Table 1.3 The values of the weights $\omega_{C 1}$ and $\omega_{C 2}$

\begin{tabular}{lll}
\hline & $\omega_{\mathrm{C} 1}$ & $\omega_{C 2}$ \\
\hline $\begin{array}{l}\text { If the chair is designed to be produced in large quantities } \\
\begin{array}{l}\text { If the chair need a custom design with a small amount of } \\
\text { production expectation }\end{array}\end{array}$ & $80 \%$ & $20 \%$ \\
\hline
\end{tabular}

- If several tasks have the relations of inclusion, an arrow with a weight of "100\%" is used. Design optimizations are often made retrospectively by taking into account new knowledge (Chenouard, 2007)

- Why the arrow from the task "Single-criterion optimization" to the task "Multi-criteria optimization" has a weight of "100\%"? Obviously, when people can perform the task of "Multi-criteria optimization", they are able to accomplish the task of "Single-criterion optimization". In other words, these two tasks have a containment relationship. In case when two tasks have a containment relationship, an arrow of a weight of " $100 \%$ " is used. Optimizations of the design are often made retrospectively, taking new knowledge into account, (Del Prete et al., 2010).

- Management of product end-of-life and recycling are critical issues in environment treatment for manufacturing enterprises so they should be considered in product lifecycle design (Bufardi et al., 2003; Ueda et al., 2005). The task « To consider the recycling issues» needs knowledge about the possibilities of recycling the materials used.

- The number of materials to be considered is not limited to three, and it may differ from case to case. In other words, this number depends on how many principal types of materials are used to build the chair.

- The three weights $\omega_{D 11}, \omega_{D 12}$ and $\omega_{D 13}$ are determined by several factors of the chair, for example, the proportion of each material used, the cost of each material used, etc.

- The task «To consider the disassembly issues » evaluate whether the designed chair can be disassembled. The easy disassembly of a product will facilitate the recycling of material used and the reuse of different parts of the chair.

- The task «To consider the interface issues » mainly considers the reuse issues of different parts of the chair. For example, if a chair has a leg broken, instead of throw away the chair and replace it by a new one, people can simply substitute the broken leg. But in order to realize the substitution of the 
broken leg, the interface between the leg and the body of the chair should be well designed. In such cases, the design of the interface should be given special attentions.

In real cases tested, each time a solution (knowledge fragment) with a higher value is chosen, and from the list of unaccomplished atom-tasks, we could find out easily which tasks should be accomplished next. Every time that $K$ reaches a state that can solve one more task, its value increases.

When knowledge reaches its final state, its value may not always be $100 \%$, but it is not critical if people are already satisfied with its current value. In the given example, if we do not have to accomplish the task of "To calculate the cost of labor", knowledge can remain in a state that its value is not $100 \%$. In such cases, people have to take some risks when they are going to the next stage of the product lifecycle.

\subsection{Conclusions}

Knowledge evaluation is a key issue in knowledge management, and this paper has presented a knowledge evaluation model in product lifecycle design. The model integrates the process of knowledge evolution and product development, and the mutual effects between knowledge and product are analyzed. Based on the theoretical definitions and models, this paper illustrates how knowledge value can be assessed by studying a specific case. In the applications of product lifecycle design, knowledge values calculated by the model can serve as important factors in a decision making system that decides which knowledge to choose and what to do next. The model could serve as a framework to describe the knowledge related activities and could be a useful tool for managing knowledge in product lifecycle design and support.

Interesting perspectives may include deeper analysis about the optimization issues of weights and dynamic product development processes.

\subsection{References}

Bernard A, Tichkiewitch S. 2008. Methods and tools for effective knowledge life-cyclemanagement. Springer, Berlin.

Bernard A, Xu Y. 2009. An integrated knowledge reference system for product development. CIRP Annals - Manufacturing Technology 58(1): 119-122.

Bufardi A, Sakara D, Gheorghe R, Kiritsis D, Xirouchakis P. 2003. Multiple criteria decision aid for selecting the best product end of life scenario. International Journal of Computer Integrated Manufacturing 16(7-8): 526-534. 
Del Prete A, Mazzotta D, Anglani A. 2010. Design optimization application in accordance with product and process requirements. Advances in Engineering Software, 41(3): 427-432.

Nacsa J, Bueno R, Alzaga A, Kovács GL. 2005. Knowledge management support for machine tool designers using expert enablers. International Journal of Computer Integrated Manufacturing 18(7): 561-571.

Nonaka I, Takeuchi H. 1995. The knowledge creating company. Oxford University Press, New York.

Perry N, Bernard A, Bosch-Mauchand M, LeDuigou J, XU Y. 2011. Eco Global Evaluation: Cross Benefits of Economic and Ecological Evaluation. Proceedings of the $18^{\text {th }}$ CIRP International Conference on Life Cycle Engineering, pp.681-686, Braunschweig, Germany.

Perry N, Candlot A, Schutte C. 2010. Collaborative Knowledge Networks Emergence for Innovation. Factors of Success Analysis and Comparison. Journal of Decision Systems 19(1): 75-91.

Ueda K, Nishino N, Nakayama H, Oda SH. 2005. Decision Making and Institutional Design for Product Lifecycle Management. CIRP Annals - Manufacturing Technology 54(1): 407-412.

Xu Y, Bernard A. 2010a. Knowledge value chain: an effective tool to measure knowledge value. International Journal of Computer Integrated Manufacturing 23(11): 957-967.

Xu Y, Bernard A. 2010b. Measurement of enterprise knowledge by state characterization. Expert Systems 27(5): 374-387.

Xu Y, Bernard A. 2011. Quantifying the value of knowledge within the context of product development. Knowledge-Based Systems 24(1):166-175. 